\title{
Drained volumetric behaviour and static liquefaction of very loose sand reinforced with synthetic fibres
}

\author{
Xidong Zhang ${ }^{1}$ and Adrian R Russell ${ }^{1, *}$ \\ ${ }^{1}$ School of Civil and Environmental Engineering, University of New South Wales, Sydney, NSW 2052, Australia
}

\begin{abstract}
Synthetic fibres may be used to reinforce soils. Fibre reinforcement may, for example, improve the mechanical behaviour of very loose sand which is usually susceptible to static liquefaction. In this study, two types of polypropylene fibres are mixed into sand to explore the effect of fibre reinforcement on drained volumetric behaviour and undrained static liquefaction. Drained and undrained stress-controlled triaxial compression tests are conducted on both unreinforced and fibre reinforced samples which are in very loose states. It is observed that, under drained compression, both unreinforced and fibre reinforced samples show volumetric contraction. In undrained compression the excess pore water pressure eventually becomes almost equal to the initial confining stress in all samples. This represents a state of liquefaction in unreinforced samples, and they become fluidised indicating the effective stress has become zero. However, in reinforced samples, the fluidised condition is absent, indicating that a conventional type of liquefaction has not occurred. It is concluded that static liquefaction in very loose sand can be prevented by fibre reinforcement, as the induced tensile stress in fibres makes the effective stress (that is the stress carried by the soil skeleton) remain above zero even when the excess pore water pressure is equal to the confining stress.
\end{abstract}

\section{Introduction}

Fibre reinforcement of soils to improve soil behaviour has become a popular topic among geotechnical engineers in recent decades. Fibre reinforcement involves adding discrete tension resisting elements into soils. A large amount of experimental research has been carried out involving monotonic shear box tests and triaxial tests [1-4]. The results indicate that the presence of fibres increases the strength of soils thus would enhance their ability to carry load in infrastructure. Fibre inclusions also alter the volumetric deformation characteristics of soils, with a variety of alterations being possible. Researchers observed that some fibre types made soils less dilative $[2,5]$, while other types made the soils more dilative [6-7].

Fibre inclusions also alter the development of soil liquefaction. Liquefaction is a catastrophic phenomenon in geotechnical engineering and occurs mostly in loose sands, sandy silts and tailings. Under undrained cyclic loading, soil element tests show that fibre reinforcement increases the liquefaction resistance of sand, demonstrated by the increasing number of load cycles required to cause liquefaction [8-10]. Shaking table tests on fibre reinforced sand give a similar conclusion, showing that fibre inclusions decrease the peak excess pore water pressure during shaking and delay the occurrence of softening and liquefaction [11]. Under undrained monotonic loading, soil elements tests have showed that fibre inclusions can eliminate the strain-softening altogether making static liquefaction impossible [12].

In this study, drained and undrained triaxial tests, as well as isotropic compression and unloading tests, are conducted on fibre reinforced sands in very loose states. The aim is to investigate the effect of fibre inclusion on the drained volumetric behaviour and undrained liquefaction resistance of very loose sand. The potential use of fibre reinforcement to avoid the onset of unstable soil behaviour and liquefaction is examined. A criterion for estimating liquefaction occurrence in fibre reinforced sand is discussed.

\section{Test materials and test conditions}

Sydney sand, a poorly graded sand, was used in all tests. Its index properties are listed in Table 1.

Table 1. Properties of Sydney sand

\begin{tabular}{cccc}
\hline $\begin{array}{c}\text { mean grain } \\
\text { size } / D_{50}\end{array}$ & $\begin{array}{c}\text { coefficient of } \\
\text { uniformity } / C_{\mathrm{u}}\end{array}$ & $\begin{array}{c}\text { coefficient of } \\
\text { curvature } / C_{\mathrm{c}}\end{array}$ & $\begin{array}{c}\text { Fine } \\
\text { conten } \\
\mathrm{t}\end{array}$ \\
\hline $0.28 \mathrm{~mm}$ & 1.94 & 0.86 & $0.36 \%$ \\
\hline $\begin{array}{c}\text { maximum void } \\
\text { ratio } / e_{\max }\end{array}$ & $\begin{array}{c}\text { minimum } \\
\text { void ratio } / e_{\min }\end{array}$ & $\begin{array}{c}\text { specific } \\
\text { gravity } / G_{\mathrm{s}}\end{array}$ & \\
\hline 0.97 & 0.6 & 2.65 & \\
\hline
\end{tabular}

Two types of polypropylene fibres having a specific gravity of 0.91 were used, including a prototype of a new fibre as well as the Loksand crimped fibre, and hereafter are referred to as Fibre (1) and Fibre (2), respectively. Photographs of the two fibres are showed in Fig. 1. Their main characteristics

\footnotetext{
* Corresponding author: a.russell@unsw.edu.au
} 
are listed in Table 2. In this study two fibre contents of $0.25 \%$ and $0.5 \%$ were used, representing the fibre mass $\left(M_{\mathrm{f}}\right)$ as a percentage of the dry sand mass $\left(M_{\mathrm{s}}\right)$. FC denotes fibre content.

Table 2. Properties of fibres used

\begin{tabular}{ccccc}
\hline $\begin{array}{c}\text { Fibre } \\
\text { type }\end{array}$ & Length & Diameter & $\begin{array}{c}\text { Tensile } \\
\text { strength }\end{array}$ & $\begin{array}{c}\text { Surface } \\
\text { properties }\end{array}$ \\
\hline Fibre (1) & $30 \mathrm{~mm}$ & $0.4 \mathrm{~mm}$ & $650 \mathrm{MPa}$ & Rough \\
Fibre (2) & $35 \mathrm{~mm}$ & $0.1 \mathrm{~mm}$ & $225 \mathrm{MPa}$ & Crimped \\
\hline
\end{tabular}
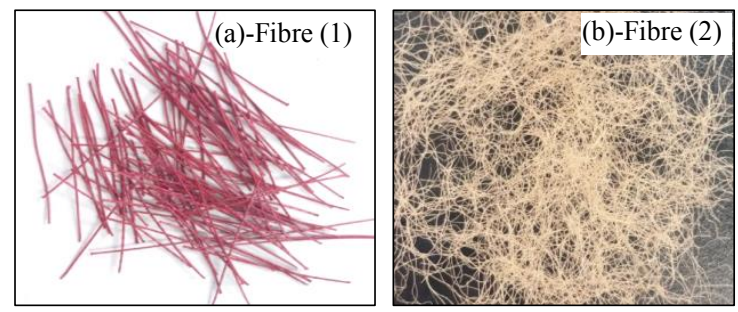

Fig. 1. Polypropylene fibres used in tests including (a) a prototype fibre and (b) the Loksand crimped fibre.

Stress-controlled triaxial tests were carried out on unreinforced and fibre reinforced sand samples in both drained and undrained monotonic compression conditions. All sand samples were saturated using the $\mathrm{CO}_{2}$ method achieving $\mathrm{B}$ values of 0.99 or greater. Before shearing, samples were isotopically consolidated to a confining pressure of $100 \mathrm{kPa}$ in excess of the pore water pressure.

Table 3. Tests performed in the study

\begin{tabular}{ccc}
\hline Test & FC (\%) & void ratio after consolidation \\
\hline CD-MC-100 & 0 & 1.0339 \\
CD-MC-100-F1 & 0.25 & 1.0131 \\
CD-MC-100-F1 & 0.5 & 1.0251 \\
CD-MC-100-F2 & 0.25 & 1.0202 \\
CD-MC-100-F2 & 0.5 & 1.0157 \\
CU-MC-100 & 0 & 1.0446 \\
CU-MC-100-F1 & 0.25 & 1.0344 \\
CU-MC-100-F1 & 0.5 & 1.0235 \\
CU-MC-100-F2 & 0.25 & 1.0260 \\
CU-MC-100-F2 & 0.5 & 1.0159 \\
\hline CU-Consolidated undrained; CD-Consolidated drained \\
M-monotonic; C-Compression; F1-Fibre (1); F2-Fibre (2)
\end{tabular}

A list of the triaxial tests performed, the FCs used and the void ratios achieved after consolidation are given in Table 3. Fibres were regarded as part of the solid phase when calculating the void ratios. It was suggested by [13] that the moist tamping method produces samples with a much lower minimum dry density than dry deposition and water sedimentation methods. Therefore, moist tamping was used in this study to prepare very loose samples, each having a diameter and length of $50 \mathrm{~mm}$. The target void ratios of samples are 1.09, greater than the maximum void ratio arrived at by dry deposition. The void ratios listed in Table 3 are values arrived at after saturation and consolidation.

\section{Test results}

\subsection{Stress and strain notations}

In discussing the test results, to separate the stresses acting on different phases, the notations of Ibraim et al. [12] for fibre reinforced sand have been adopted and are defined in Table 4. The stresses of different phases are related as follows:

$$
\begin{gathered}
p=p^{*}+u=p^{\prime}+p_{f}+u \\
q=q^{*}=q_{f}+q^{\prime}
\end{gathered}
$$

In Eq. (1) $u$ is the excess pore water pressure. The detailed calculation of stresses and strains in axisymmetric triaxial conditions is detailed further by Ibraim et al. [12]. Obviously $p$ is equal to $p^{*}$ in drained conditions as there is no excess pore water pressure generated. $q$ is always equals to $q^{*}$ regardless of the drainage condition.

Table 4. Notations and their denotations

\begin{tabular}{cc}
\hline Notation & Denotation \\
\hline$p, q$ & Total mean stress, deviatoric stress on the composite \\
$p^{*}, q^{*}$ & Effective mean stress, deviatoric stress on the composite \\
$p^{\prime}, q^{\prime}$ & Effective mean stress, deviatoric stress on sand skeleton \\
$p_{f}, q_{f}$ & Mean stress, deviatoric stress contributed by fibres \\
$\varepsilon_{\mathrm{v}}, \varepsilon_{\mathrm{q}}$ & Volumetric strain, shear strain \\
\hline
\end{tabular}

\subsection{Isotropic compression and unloading tests}

Isotropic compression and unloading tests were conducted on both unreinforced and fibre reinforced sand samples using $50 \mathrm{~mm}$ diameter unlubricated end platens. The results are showed in Fig. 2.

Under isotropic compression the fibre reinforced sand samples show more volumetric contraction than the unreinforced samples (Fig. 2). The presence of fibres obviously increases the isotropic compression of sand, especially Fibre (2). The amount of isotropic compression increases with fibre content. In Fig. 2 the volumetric expansion during unloading is linear with the logarithmic of $\sigma_{3}^{\prime}$ and may be described using equation (3).

$$
\Delta \varepsilon_{v}=a \ln \left(\frac{\sigma_{3 f}^{\prime}}{\sigma_{3 i}^{\prime}}\right)
$$

where $\sigma_{3 \mathrm{i}}^{\prime}$ denotes the initial effective confining pressure acting on the sample and $\Delta \varepsilon_{\mathrm{v}}$ denotes the volumetric strain. The parameter $a$ of each sample tested is showed in Table 5. Parameter $a$ for unreinforced and Fibre (1) reinforced sand samples are almost equal, while for Fibre (2) reinforced sand samples it is larger. Fibre (2) reinforced sand samples exhibit greater volumetric expansion upon a reduction to isotropic confining stress. In general, during isotropic compression and unloading, the fibres are not in tension thus do not contribute to the stresses acting on the soil skeleton in a significant way. The different volumetric responses observed are most 
likely a symptom of different soil structures being formed in the samples for the different fibre types.

Table 5. Parameter $a$ in the logarithmic function linking volume strain upon unloading to effective confining pressure.

\begin{tabular}{ccccc}
\hline $\begin{array}{c}\text { Sample } \\
\text { No. }\end{array}$ & Fibre type & $\begin{array}{c}\text { Fibre } \\
\text { content }\end{array}$ & $\begin{array}{c}\text { Initial void } \\
\text { ratio }\left(e_{\mathrm{o}}\right)\end{array}$ & $a$ \\
\hline 1 & N/A & 0 & 1.0387 & 0.3337 \\
2 & Fibre (1) & $0.25 \%$ & 1.0266 & 0.3366 \\
3 & Fibre (1) & $0.50 \%$ & 1.0144 & 0.3341 \\
4 & Fibre (2) & $0.25 \%$ & 1.0185 & 0.3828 \\
5 & Fibre (2) & $0.50 \%$ & 1.0043 & 0.4073 \\
\hline
\end{tabular}

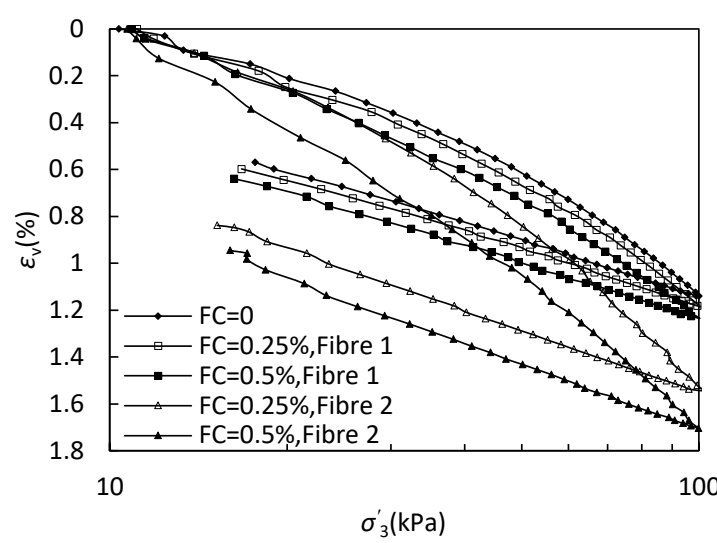

Fig. 2. Volumetric strain under isotropic compression and unloading.

\subsection{Drained triaxial compression}

Drained compression test results show that adding Fibre (1) and (2) into very loose sand significantly increases the strength of the sand. The deviatoric stress of the reinforced sand continuously goes up, even as a shear strain of $40 \%$ is approached, indicating the fibres continue to add strength as deformation increases (Fig.3 (a)). Fibre (2) has a much greater reinforcing effect than Fibre (1). At a shear strain of $40 \%$, the deviatoric stress of the sample reinforced by Fibre (2) (with $0.5 \%$ FC) is increased by about $330 \%$ compared with unreinforced sand, while the deviatoric stress increase for Fibre (1) is a more modest $160 \%$. All samples are in a very loose state, so they exhibit volumetric contraction under drained compression (Fig.3 (b)). The presence of Fibre (2) makes the sand significantly more contractive. During shear the fibres act in tension and a greater shearinduced contraction results from the added confinement provided by the fibres on to the soil skeleton [14]. At large shear strains, the unreinforced samples exhibit a constant volumetric condition while fibre reinforced samples continue to contract, especially the ones reinforced by Fibre (2).

Under drained compression, the stress path of unreinforced sand obeys $\delta q / \delta p=3$, and so does the stress path of fibre-sand composite. However, the stress path of the sand matrix in fibre reinforced sample is influenced by the extra confinement provided by the fibre stress. Specifically, with increasing fibre induced confinement acting on sand particles, the sand matrix stress path no longer moves along a single line of slope 3 under drained conditions, but shifts rightwards as illustrated in Fig. 4.
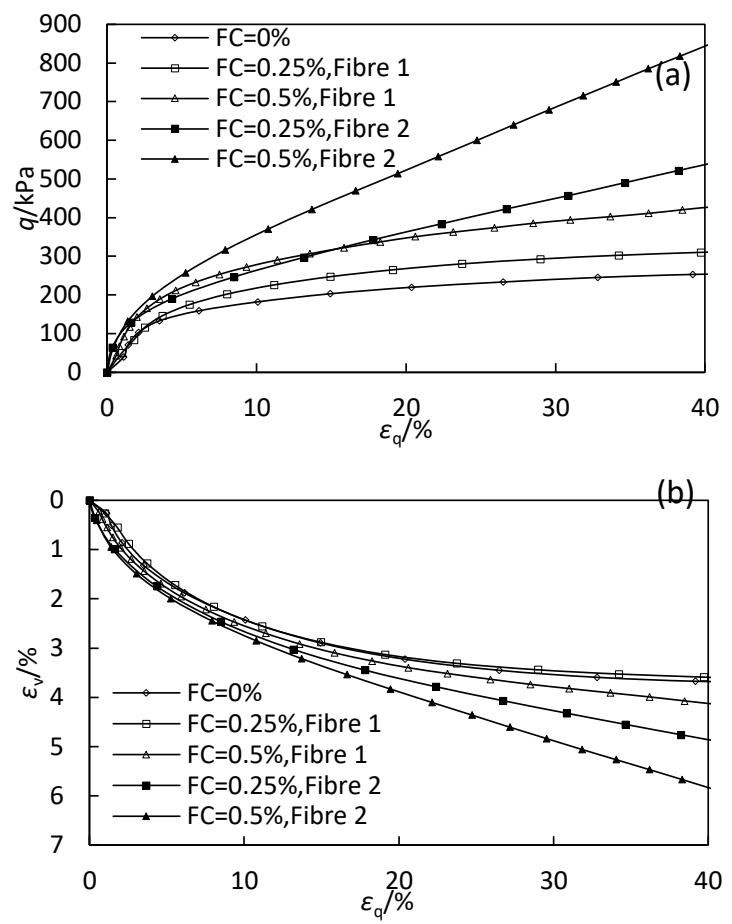

Fig. 3. Drained triaxial compression test; (a) Deviator stress-shear strain, (b) Volumetric strain-shear strain.

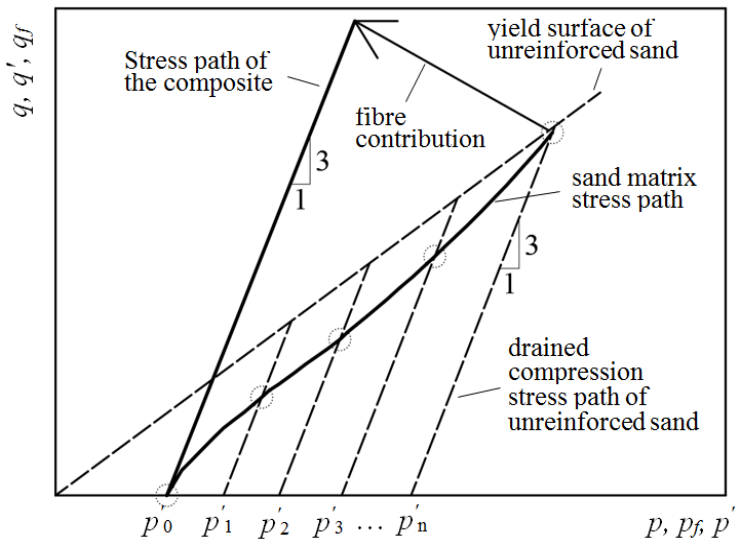

Fig. 4. Progress of the sand matrix stress path in fibre reinforced sand under drained triaxial compression.

In continuous drained shearing the stress state of an unreinforced sand approaches the critical state as $\delta \varepsilon_{\mathrm{v}} / \delta \varepsilon_{\mathrm{q}}=0$, evidenced by the almost horizontal volumetric strain curve in Fig.3 (b). However, in the fibre reinforced samples, especially those reinforced by Fibre (2), the volumetric strain continuously decreases even as the shear strain approaches $40 \%$. As mentioned before, this continuous volumetric contraction results from the continuous increase of induced fibre stress which applies a continuously increasing confinement to the sand particles. Test data shows, after shear strain reaches $20 \%$ and goes on, $\delta \varepsilon_{\mathrm{v}} / \delta \varepsilon_{\mathrm{q}}$ of Fibre (2) reinforced sand (with FC contents 
of $0.25 \%$ and $0.5 \%$ ) remains stable at around 0.08 and 0.1 respectively.

\subsection{Undrained triaxial compression}

Fig.5 (a) shows that, under undrained compression, two different behaviours are observed. In the unreinforced sample, and the samples reinforced with Fibre (1), strain softening occurs in the early stages of shear (evidenced by a peak in the deviator stress), and then a drop of the deviator stress occurs along with a rapid development of shear strain and the excess pore water pressure ratio $\left(r_{\mathrm{u}}=\Delta u / \sigma_{3 \mathrm{c}}^{\prime}\right)$ increases to almost 1 . The observed behaviour is typically related to static liquefaction. Adding Fibre (1) into sand increases both the peak deviatoric stress and the residual deviatoric stress. Fibre (1) also delays the onset of instability as it increases the stress ratio, shear strain, and excess pore water pressure ratio at the initiation (Table 6).
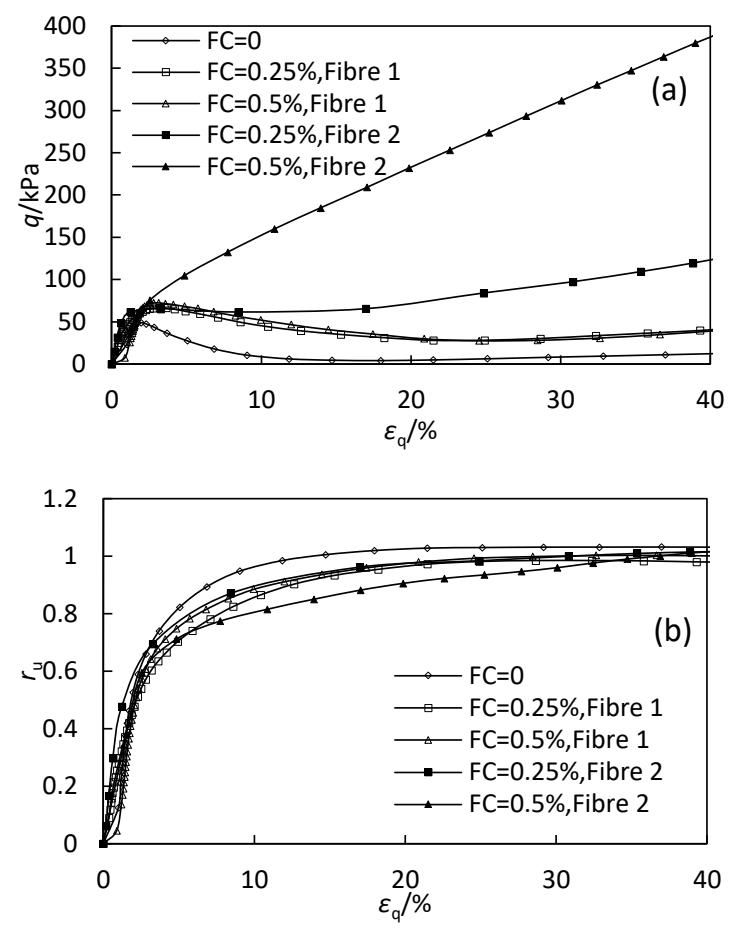

Fig. 5. Undrained triaxial compression test; (a) Deviator stress-shear strain, (b) Excess pore water pressure ratioshear strain.

Table 6. Test data at the initiation of instability.

\begin{tabular}{cccccc}
\hline $\mathrm{FC}$ & $q(\mathrm{kPa})$ & $p^{\prime}(\mathrm{kPa})$ & $q / p^{\prime}$ & $\varepsilon_{\mathrm{q}}(\%)$ & $r_{\mathrm{u}}$ \\
\hline 0 & 48.98 & 62.81 & 0.78 & 2.12 & 0.52 \\
$0.25 \%$ & 66.83 & 61.87 & 1.08 & 3.04 & 0.60 \\
$0.50 \%$ & 72.67 & 60.41 & 1.20 & 3.00 & 0.64 \\
\hline
\end{tabular}

Reinforcement using Fibre (2) produces a very different response. A much greater deviator stress prevails at large shear strain, with a peak in the deviatoric stress being absent (Fig. 5a, Fig.6). From Fig.5 (b) it can be seen that $r_{\mathrm{u}}$ keeps going up and eventually approaches 1 . It is well known that $r_{\mathrm{u}}=1$ is associated with a fluidized state in unreinforced sand. Fluidization was not observed at $r_{\mathrm{u}}=1$ in the Fibre (2) reinforced sand because the fibres continued to provide confinement to the soil skeleton.

The two different behaviours observed in the samples reinforced by two different fibres illustrate the various degrees of contribution made by the fibres. In the reinforced samples by Fibre (1), only a limited tensile stress is induced in the fibres. As a result, Fibre (1) is not able to prevent the static liquefaction and instability. The addition of Fibre (1) does delay the occurrence of instability although it does increase the residual strength slightly. Fibre (2) supplies more confinement to the sand matrix which is attributed to the greater tensile stress induced in the fibres. However, it should not be ignored that in Fibre (2) reinforced samples with FC of $0.25 \%$, a short-term instability occurs being with rapid development of shear strain, although a significant drop of deviator stress is not observed. Unlike the Fibre (1) reinforced samples, the instability stops quickly and the deviator stress increases afterwards as observed in Fig.5 (a). Fig.5 (b) shows that the excess pore water pressures in the Fibre (2) reinforced samples continuously increase, which indicates that the sand matrix also keeps tending to contract.

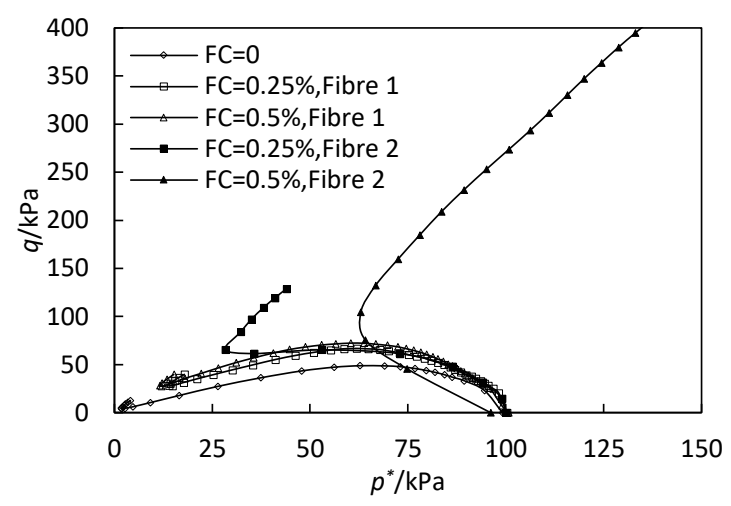

Fig. 6. Stress paths of all samples under undrained triaxial compression.

\subsection{Criterion for liquefaction estimation}

The excess pore water pressure ratio $\left(r_{\mathrm{u}}\right)$ is widely used as a criterion to signify liquefaction occurrence. In unreinforced sand, when $r_{\mathrm{u}}$ reaches 1 , the effective stress carried by soil particles becomes zero and the sand sample become fluidized. However, in this study, sand reinforced by Fibre (2) remains stable even after $r_{\mathrm{u}}$ becomes (almost) 1, which indicates that using this definition to signify liquefaction occurrence is no longer suitable.

Stress equilibrium in fibre reinforced sand under undrained shear is complicated, as showed by Eq. (1). The mean stress in a sand-fibre composite is carried by sand particles, pore water as well as fibres. $r_{\mathrm{u}}=1$ no longer signifies a zero effective stress on the sand skeleton. The stress contribution from fibres makes 
$p^{*}=p^{\prime}+p_{f}$, that is the effective mean stress acting on the composite, as well as $p^{\prime}$, that is the effective mean stress acting on the sand skeleton, stays above zero when $r_{\mathrm{u}}=1$. Consequently, a fluidized condition may be absent in fibre reinforced sand even as $r_{\mathrm{u}}$ approaches 1 . From the observations in this study, in fibre reinforced sand, when $r_{\mathrm{u}}=1$, the occurrence of fluidized state is controlled by $p_{f}$. For a fibre reinforced sand to fluidize and liquefy it is necessary for $p_{f}$ to decrease to (or become very close to) zero at the same time that $r_{\mathrm{u}}$ approaches 1 . This is the case for Fibre (1) reinforced sand. However, if a significant $p_{f}$ prevails as $r_{\mathrm{u}}$ approaches 1 the fluidized state will not occur. The reinforced sand will remain stable as was the case for Fibre (2) reinforced samples.

These differences associated with reinforcement by the two fibre types are mainly due to the properties of the two fibre types. Fibre (2) has a much greater aspect ratio (350) that is the ratio of fibre length to diameter, than Fibre (1) (75). This greater aspect ratio results in more fibre surface area being in contact with the sand particles as generally, under the same fibre content, the number of fibres included in the sample reinforced by Fibre (2) is much more than Fibre (1) reinforced sample. The greater surface contact enabled Fibre (2) to mobilise more capacity through greater frictional interaction with the sand particles, for both drained and undrained conditions.

\section{Conclusions}

Isotropic compression and unloading tests, as well as drained and undrained triaxial compression tests, were completed to investigate the effect of fibre reinforcement on the behaviour of very loose sand with and without fibre reinforcement. The conclusions obtained from the experimental study are listed below:

The presence of fibres increases the drained strength of loose sand. Both unreinforced and fibre reinforced samples exhibit volumetric contraction under drained compression, while adding fibres makes sand more contractive due to the extra confinement provided by the tensile stress induced in fibres. Fibre addition makes loose sand more compressive under isotropic loading. The presence of Fibre (2) also causes sand to become more expansive under isotropic unloading. Fibre inclusions change the stress path of the sand matrix under drained triaxial compression away from $\delta q / \delta p=3$.

Under undrained compression, static liquefaction related instability occurs in both unreinforced and Fibre (1) reinforced samples, but the inclusion of Fibre (1) delays the occurrence of the instability. However, static liquefaction induced strain softening is prevented by the reinforcement of Fibre (2). Fibre (2) is more able to go into tension and impose a confining stress on the sand matrix than Fibre (1).

Reinforced samples by Fibre (2) remain stable even after excess pore water pressure ratio approaches 1. This indicates that the excess pore water pressure ratio becoming 1 is not a suitable indicator of liquefaction occurrence in fibre reinforced sands. Effective stress equilibrium in fibre reinforced sand is more complicated than ordinary sand. When the excess pore water pressure ratio reaches 1 , the effective stress carried by sand skeleton may remain above zero and a fluidized condition is absent.

Financial support of this research was provided by the University of New South Wales in Australia, and this work was also supported by China Scholarship Council.

\section{References}

1. D. H. Gray, H. Ohashi. J Geotech Eng-ASCE, 109, 3: 335-353 (1983).

2. R. L. Michalowski, A. Zhao. J Geotech EngASCE, 122, 3: 226-234 (1996).

3. S. R. Kaniraj, V. G. Havanagi. J Geotech Geoenviron, 127, 7: 574-584 (2001).

4. A. Diambra, E. Ibraim. Géotechnique, 65, 4 : 296-308 (2015).

5. R. L. Michalowski, J. Čermák. J Geotech Geoenviron, 129, 2: 125-136 (2003).

6. I. M. C. F. G. Falorca, M. I. M. Pinto. Geosynth Int, 18, 1: 2-11 (2011).

7. A. Diambra, E. Ibraim, D. M. Wood, A. R. Russell. Geotext Geomembranes, 28, 3: 238-250 (2010).

8. N. Unnikrishnan, K. Rajagopal, N. R. Krishnaswamy. Geotext Geomembranes, 20, 2: 117-133 (2002).

9. R. Noorzad, P. F. Amini. Soil Dyn Earthq Eng, 66: 281-292 (2014).

10. T. Eskisar, E. Karakan, S. Altun. Procedia Eng, 161: 538-542 (2016).

11. B. K. Maheshwari, H. P. Singh, S. Saran. J Geotech Geoenviron, 138, 7: 831-840 (2012).

12. E. Ibraim, A. Diambra, D. M. Wood, A. R. Russell. Geotext Geomembranes, 28, 4: 374-385 (2010).

13. K. Ishihara. Géotechnique, 43, 3:351-451 (1993).

14. A. Diambra, E. Ibraim, A. R. Russell, D. M. Wood. Int J Numer Anal Met, 37, 15: 2427-2455 (2013). 